\title{
Lessons about the reliability of congenital syphilis and vertical HIV transmission data learned from case reviews in Uruguay: a cross-sectional study
}

\author{
Susana Cabrera ${ }^{1}$, Mariangela Freitas Silveira $2^{2^{*}}$, Ana Visconti ${ }^{3}$, Fabian García ${ }^{3}$, Rafael Aguirre ${ }^{4}$
} Rodolfo Gomez Ponce de Leon ${ }^{2}$, Jorge Quian ${ }^{5}$ and Suzanne J. Serruya ${ }^{2}$

\begin{abstract}
Background: In Uruguay it is mandatory to review all cases of positive HIV or reactive syphilis tests in pregnancy and peripartum. We compared the rates of mother-to-child transmission of syphilis and HIV detected by case reviews to those obtained from the usual surveillance system and described the characteristic of vertical transmission cases.

Methods: This is a cross-sectional study performed with secondary data obtained from official government sources, for all the country cases of maternal to child transmission of HIV and syphilis from 2012 to 2017, with descriptive analyses. For congenital syphilis analyses, the following pregnancy characteristics were investigated: number of antenatal checks, gestational age at pregnancy diagnosis, gestational age at syphilis test and diagnosis, adequate treatment, and treatment of partners. Sociodemographic characteristics included type of health care (public/ private), maternal age, distribution of ethnic minorities, maximum educational attainment, presence of partner, planned pregnancy, drug and alcohol use, domestic violence, previous maternal diagnosis of syphilis, and previous children with congenital syphilis.

Results: Coverage of syphilis case reviews increased from $82 \%$ in 2014 to $97.4 \%$ in 2017. For HIV, this coverage reached 100\% in 2017 and elimination of mother to child transmission was achieved. A marked decline in congenital syphilis was noted in the public health care sector, especially in the capital Montevideo, whereas the private sector has remained below the elimination target. Variables related with congenital syphilis in exposed children were late pregnancy diagnosis, $<5$ antenatal checks, delayed diagnosis of gestational syphilis, lower rate of correct treatment for gestational syphilis, untreated partner, low maternal schooling, unplanned pregnancy, history of syphilis, and having other children with syphilis.

Conclusion: The use of case reviews provided knowledge regarding the accurate number of mother-to-child transmission cases and the evolution of elimination of mother to child transmission in the country. The results suggest that rates must be adjusted, providing an opportunity to improve the reliability of surveillance data, and point the need to address specific gaps in order to improve the quality of care during pregnancy, delivery, and the neonatal period.
\end{abstract}

Keywords: Syphilis, Congenital, HIV, Vertical transmission

\footnotetext{
* Correspondence: mariangelafreitassilveira@gmail.com

${ }^{2}$ Latin American Center of Perinatology, Women and Reproductive Health,

Montevideo, Uruguay

Full list of author information is available at the end of the article
}

(c) The Author(s). 2019 Open Access This article is distributed under the terms of the Creative Commons Attribution 4.0 International License (http://creativecommons.org/licenses/by/4.0/), which permits unrestricted use, distribution, and reproduction in any medium, provided you give appropriate credit to the original author(s) and the source, provide a link to the Creative Commons license, and indicate if changes were made. The Creative Commons Public Domain Dedication waiver (http://creativecommons.org/publicdomain/zero/1.0/) applies to the data made available in this article, unless otherwise stated. 


\section{Key messages}

- Case reviews of congenital syphilis in Uruguay have produced better knowledge regarding the accurate number of cases.

- Case reviews allow assessments of EMTCT status.

- Surveillance rates must be adjusted according to case reviews.

- Several prevention strategies could be implemented at the primary care level to improve care and reduce congenital syphilis.

\section{Background}

The global community has set the elimination of motherto-child transmission (EMTCT) of HIV and syphilis as a public health priority. In 2007, an initiative for the EMTCT of HIV and syphilis led by the World Health Organization (WHO) was launched, based on a foundation of quality maternal and child health services, as advocated by the Millennium Development Goals (MDGs), and aimed at reducing child mortality and improving maternal health [1-3]. Those goals were also supported by the Pan American Health Organization (PAHO) since 2010 with the Plan of Action for Elimination of Motherto-Child Transmission of HIV and Congenital Syphilis [4].

In any country, specific strategies for dual EMTCT of HIV and syphilis are influenced by local characteristics, including HIV and syphilis epidemiology, service delivery models, coverage of health services, and available resources [1].

With the aim of advancing toward universal coverage, a health system reform was begun in Uruguay in 2005 with the establishment of an Integrated National Health Care System (Sistema Nacional Integrado de Salud, SNIS) and creation of the National Health Insurance (Seguro Nacional de Salud, SNS). The SNS translated into increased population access to public health care services. The national health care policy, including health surveillance and inspection activities, is managed by the Ministry of Public Health [5]. Regarding mother/ child health, $99 \%$ of deliveries in Uruguay are institutional and attended by skilled health professionals. The national health care policy emphasizes early antenatal care (starting at $<12$ weeks of gestational age) as well as an increase in the number of antenatal checks. According to the Perinatal Information System (Sistema Informático Perinatal, SIP), the rate of early antenatal care was $78 \%$ in 2016 , with $93 \%$ of pregnant women having more than 5 antenatal checks [5].

Elimination of vertical syphilis and HIV transmission is among the 15 critical problems to be prioritized as part of the Ministry of Public Health's strategic plan for 2020 [6]. Integration of sexually transmitted infections (STI) and HIV prevention into the country's sexual and reproductive health policy should be a special highlight of the EMTCT strategy in Uruguay. In 1997, syphilis and HIV testing during pregnancy became mandatory in the country, along with the provision of antiretroviral therapy (ART) and feeding formulas for infected mothers [6]. Since 2002, rapid syphilis and HIV tests have been routinely performed in the country's birth centers. Rapid testing was extended to the primary care level in 2013 and penicillin is available at the clinics after the first positive test both for the pregnant women and their partners. In that same year, a third syphilis and HIV screening was introduced, so that screening is now performed at the first antenatal check and during the second and third pregnancy trimesters [6]. Since 2014, the presence of sexual partners in antenatal visits at least once in the first and third trimesters has been encouraged, with advice to perform syphilis testing in accordance with the national recommendations for EMTCT of syphilis and HIV [7].

A crucial measure instituted along this period (in 2013) was the mandatory reporting and review of cases with positive HIV tests or reactive syphilis tests during the pregnancy and peripartum, with incorporation of these reviews as production targets (i.e., part of a performance-based incentive scheme) for all SNIS institutions [8]. Individual congenital syphilis case reviews are recommended by WHO to evaluate the use of consistent and correct case definitions, as well to detect under or overreporting [1]. Since 2017, a new production target, named "Boy, Girl, and Woman," focusing on pregnancy and on the monitoring of children until 3 years of age, introduced mandatory offer of VDRL/RPR and HIV testing for women and their partners across the SNIS [https://www.paho.org/uru/index.php?option= com_docman\&view=document\&slug=ordenanza-n1119-2018-msp-etmi-plus\&layout $=$ default $\&$ alias $=606$ ordenanza-n-1119-2018-msp-etmi-plus\&category_slug= publications\&Itemid=307 ]. This target serves as an incentive to the review of cases by health care institutions.

Given this scenario, the objective of the present work was to compare the rates of mother-to-child transmission of syphilis and HIV detected by case reviews to those obtained from the usual surveillance system. Also, case reviews were examined to identify gaps in care processes and variables associated with vertical transmission, generating information that can be useful for training and the implementation of corrective actions.

\section{Methods}

This is a cross-sectional study performed with secondary data obtained from public government sources: electronic live birth certificate (LBC, which provides information on syphilis and HIV test results), SIP, DST-HIV-AIDS Programs, epidemiological data on HIV/AIDS in Uruguay 
(for the years 2012-2017), vital statistics, and congenital syphilis and HIV case review database. Uruguay is a South American country with a population of $3,480,222$, with 95\% living in urban areas [9]. The country has a high human development index (HDI), of 0.795 [10], and was classified by the World Bank as a high income country since 2013 [11]. All the congenital syphilis and Maternal to child transmission of HIV cases from 2014 to 2017 were included. Congenital syphilis cases were defined using the WHO surveillance definition: a live birth or fetal death at $>20$ weeks of gestation or $>500 \mathrm{~g}$ (including stillbirths) born to a woman with positive syphilis serology and without adequate syphilis treatment, or a live birth, stillbirth or child aged $<2$ years born to a woman with positive syphilis serology or with unknown serostatus, and with laboratory and/or radiographic and/or clinical evidence of syphilis infection (regardless of the timing or adequacy of maternal treatment) [1]. For the vertical transmission of HIV, diagnosis was confirmed by nucleic acid testing.

Congenital syphilis analyses also included a description of the following pregnancy characteristics: women with < 5 antenatal checks, mean gestational age at pregnancy diagnosis in weeks, pregnancy diagnosis at $>14$ weeks, mean gestational age at first syphilis diagnosis in pregnancy, first syphilis test at $>14$ weeks, mean gestational age at the diagnosis of syphilis during pregnancy, diagnosis of syphilis at delivery or puerperium, adequate treatment, and treatment of partners (yes or no).

Sociodemographic characteristics were also described: type of health care (public/private), mothers with age $<19$ years, distribution of ethnic minorities, maximum educational attainment (illiterate, incomplete elementary, complete elementary, incomplete high school, complete high school, university level), living with partner, planned pregnancy, drug and alcohol use, domestic violence, previous maternal diagnosis of syphilis, and previous children with congenital syphilis.

Rates of congenital syphilis and vertical transmission of HIV were described. Antenatal care and sociodemographic characteristics (all variables collected at the audits), as means or percentages, are described according to the congenital syphilis outcome. Characteristics of vertical transmission of HIV cases were described individually.

Information for the calculation of EMTCT indicators for HIV and congenital syphilis is obtained from the bureau for epidemiological surveillance (DEVISA) and the SIP, mandatorily used by all public and private pregnancy care services in Uruguay. Birth center databases provide aggregate national data or specific data sets for different provinces, non-metropolitan areas, or by health care sector (public or private).

\section{Case reviews}

Two Ministry of Health Program Areas (STI-HIV/AIDS and Sexual and Reproductive Health) are in charge of analyzing case review data and of producing reports regarding process and performance indicators. The following actions have been developed by the Program Areas in association with the case reviews: design of case review form, validation of case review form [12], design of an online tool for submission of syphilis case reviews, and inclusion of information regarding completed syphilis and HIV case reviews as part of the production targets. Case reviews are triggered by the identification of a "reactive" syphilis or HIV test in women during the pregnancy, labor, or puerperium, or in neonates.

The syphilis case review form must be filled for all women with a reactive syphilis test (non-treponemal or rapid treponemal test) during pregnancy, labor, or puerperium, and for all newborns with a reactive nontreponemal cord blood test. HIV case review forms are completed for all women with HIV diagnosis who become pregnant, or for those diagnosed during pregnancy, labor, or early puerperium. HIV-exposed children are followed until HIV infection is confirmed or ruled out. The mothers are also followed-up regarding adherence to ART.

The consolidated SIP database and LBC data are examined in search of "reactive" syphilis and HIV tests. This information is contrasted to the case reviews submitted by health care institution. This triangulation allows the construction of a case review database, with identification of missing cases (not spontaneously submitted), which can then be requested. For the case reviews, specific forms are filled and submitted by health care providers via e-mail to the STI-HIV/AIDS Program Area. In 2017, an online tool was created for syphilis case reviews, with assignment of a username to each health care provider.

The technical department in charge of delivery/C-section or abortion care at each institution performs the case review. The form must include additional data from the clinical history and the SIP. The institution where the final pregnancy care was provided is in charge of submitting to the Ministry of Health the completed case review form including a copy of SIP history no later than 45 days following the birth or stillbirth.

By analyzing these records, the following information can be obtained: socio-demographic information, information regarding current pregnancy (gestational age at first antenatal check, number of checks), information provided at syphilis or HIV testing (gestational age at first test and at first test with reactive result, results of non-treponemal tests expressed as a titer, results of follow-up, types of tests performed), information regarding treatment, and data about the partner, the delivery, 
and the newborn. For the present study, the analysis of years 2015-2017 included complementary information obtained from SIP regarding ethnicity, education, use of alcohol and drugs, violence, and having a stable partner.

\section{Results}

Coverage of syphilis case reviews (submission of the form in relation to the total number of reactive syphilis tests) increased from $82 \%$ in 2014 to $95.3 \%$ in 2015 , 97.3\% in 2016 and $97.4 \%$ in 2017. The coverage of HIV case reviews was $97 \%$ in 2014, $98 \%$ in 2015 and $100 \%$ in 2016 and 2017. For HIV, it should be noted that, even in the absence of a case review, $100 \%$ of the exposed children are followed-up.

Table 1 shows the results of EMTCT impact indicators for congenital syphilis using as data source the routine reporting system (SIP) vs. case reviews, as well as data related to vertical HIV transmission obtained from case reviews performed from 2012 to 2017. The data shows that, for HIV, the vertical transmission rate reached the EMTCT goal of $<2 \%$ in the 2 final years of analysis.

The congenital syphilis rate obtained from case reviews was consistently higher than that obtained from the usual system. This indicates that some reactive tests included for case review were not reported to the surveillance system as cases of congenital syphilis.

Regarding congenital syphilis, Fig. 1 shows a marked decrease in the public health care sector, resulting in a positive impact on the decline observed at the national level. In turn, the private sector has remained below or close to the elimination rate of $0.5 \%$. The reduction in the national rate of congenital syphilis associated with the public sector resulted from a major decline recorded in the capital city of Montevideo. Conversely, an increase was observed in the country interior. For the private sector, a decline was detected in the last year of the series for both the overall national rate and Montevideo, with achievement of the elimination target including the country interior. (Fig. 1).
Table 2 shows a description of pregnancy characteristics for congenital syphilis cases after a diagnosis in pregnancy in 2014, 2015, 2016 and 2017. We can observe a higher prevalence of delayed pregnancy diagnosis, fewer than 5 antenatal checks, delayed syphilis diagnosis or diagnosis of gestational syphilis at delivery or puerperium, lower rate of correct treatment of congenital syphilis, and untreated partner.

In the last 3 years several variables that characterize sociocultural vulnerability were incorporated into the analysis. This showed that, in exposed children, the main characteristics related with congenital syphilis were public health care, unplanned pregnancy, drug use, history of syphilis, and having previous children with congenital syphilis (Additional file 1: Table S1).

Regarding mother-to-child transmission (MTCT) of HIV, a decrease was recorded at the national level, from $6.3 \%$ in 2012 to $1.9 \%$ in 2017 , slightly higher than the 2016 rate (1.5\%). The rate was below the elimination target in the 2 final years, but in 2017 it was higher in the public health care sector (Fig. 2).

We observed that, in the period of 2012-2016, a lower proportion of women with HIV had an adequate number of antenatal checks ( $\geq 5$ checks), but in 2017 there was an increase of 3.2 percentage points. Early pregnancy diagnosis $(\leq 14$ weeks) was also found for a lower proportion of women. The increase in HIV testing coverage persists, and remains above 95\%, while HIV prevalence has remained stable during this period (data not shown).

The coverage by ART prophylaxis for MTCT was high, as was the coverage by ART, with a constant gestational age at the start of ART. A sustained increase in the proportion of women presenting with undetectable viral load at delivery was also noted $(\leq 4$ weeks prior to delivery), as well as in the percentage of women who effectively continued ART after delivery. The rate of Csections among those with indication (data not shown) had a decrease of 6.4 percentage points in 2017.

All the children with HIV were reported in the routine information system. HIV case reviews aimed at detecting

Table 1 Annual rate of congenital syphilis cases and incidence of vertical HIV transmission reported per 1000 live births, based on case review data, Uruguay, 2012-2017

\begin{tabular}{|c|c|c|c|c|c|c|}
\hline \multirow[t]{2}{*}{ Data source } & \multicolumn{6}{|l|}{ Year } \\
\hline & 2012 & 2013 & 2014 & 2015 & 2016 & 2017 \\
\hline CS rate - routine reporting system (SIP) & - & $1.7 / 1000$ & $1.2 / 1000$ & $1.1 / 1000$ & $1.0 / 1000$ & $0.8 / 1000$ \\
\hline CS rate - case reviews & - & $2.0 / 1000$ & $2.3 / 1000$ & $1.8 / 1000$ & $1.5 / 1000$ & $1.1 / 1000$ \\
\hline No. births & 48,059 & 48,681 & 48,368 & 48,915 & 47,058 & 43,036 \\
\hline No. exposed children (born from HIV-infected mothers) & 142 & 124 & 136 & 112 & 130 & 102 \\
\hline No. children infected & 9 & 2 & 4 & 2 & 2 & 2 \\
\hline Vertical transmission rate & 6.3 & 1.6 & 2.9 & 1.8 & 1.5 & 1.9 \\
\hline HIV transmission rate & 0.19 & 0.04 & 0.08 & 0.02 & 0.04 & 0.05 \\
\hline
\end{tabular}

CS congenital syphilis 


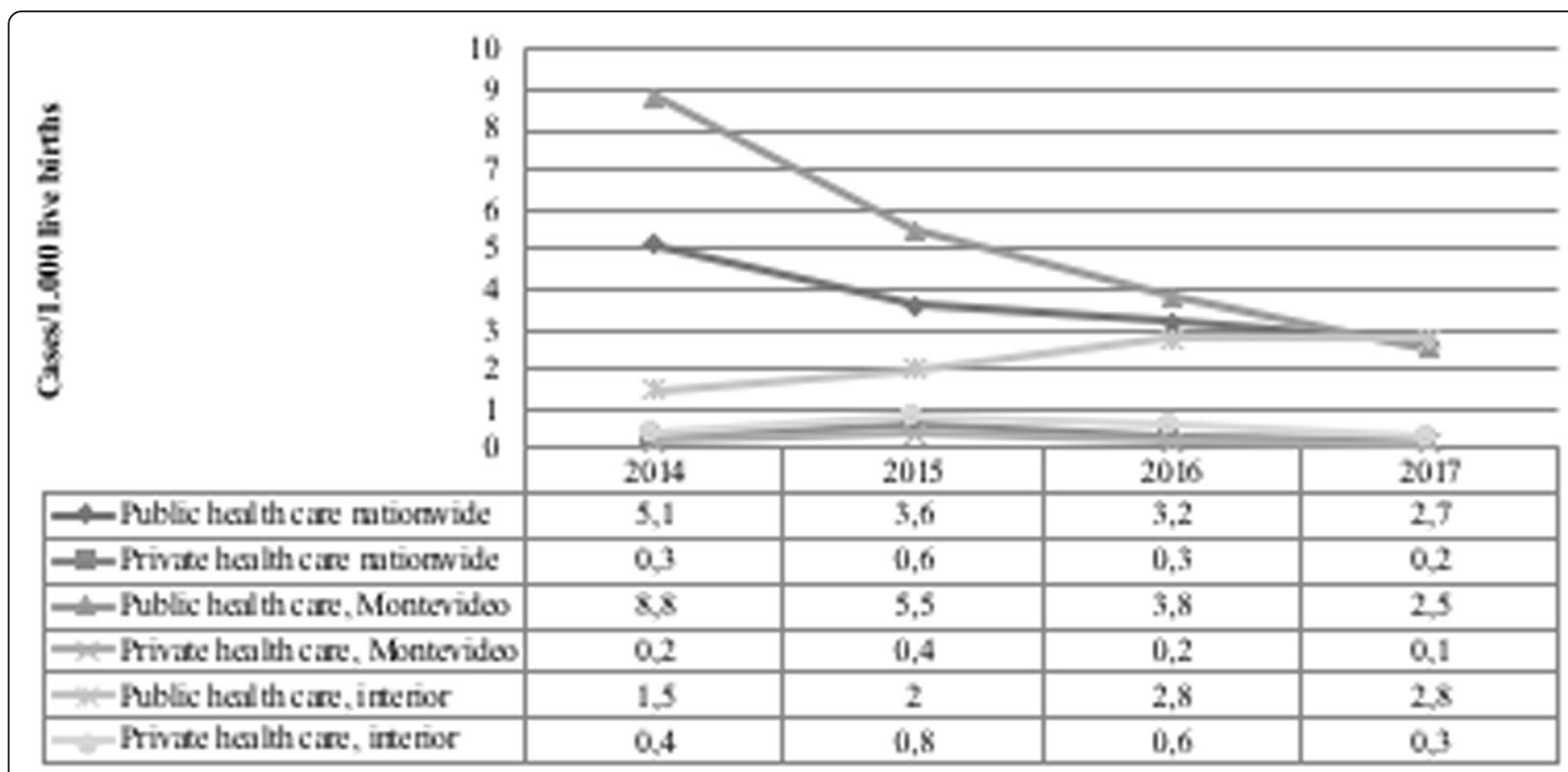

Fig. 1 Evolution of congenital syphilis infection rate according to health care sector and geographic location in Uruguay, 2014-2017

system failures or bottlenecks leading to vertical transmission of HIV infection. Additional file 1: Table S2 shows some characteristics of the children with perinatal HIV infection in 2013-2017 according to the case reviews. HIV diagnosis was delayed in the mothers, with one case diagnosed at delivery and two in the puerperium. There were three cases of seroconversion during the pregnancy and one possible late conversion during pregnancy or breastfeeding. In three women, no MTCT prevention strategies were used, and two only received intrapartum AZT. In two out of four women with information on viral load prior to the delivery, cell count was $<1000$ copies $/ \mathrm{mL}$.

\section{Discussion}

In Uruguay, the rate of congenital syphilis detected by case reviews was higher than that detected with the routine reporting system for all years investigated, showing a persistent underreporting issue. This finding reinforced the need to maintain routinely congenital syphilis casestudies as a surveillance tool. It was also observed that the country has not yet reached the congenital syphilis elimination target. For HIV, however, the EMTCT target was reached in the 2 last years of analysis. The founded congenital syphilis rate is is compatible with the Region of America's rate of 1.7 cases per 1000 live births in 2015. In 2015, 22 countries and territories in the Region

Table 2 Pregnancy characteristics among congenital syphilis cases after a maternal diagnosis, Uruguay, 2014-2017

\begin{tabular}{|c|c|c|c|c|}
\hline \multirow[t]{2}{*}{ Variable } & $\begin{array}{l}2014 C S=107 \\
\text { no } C S=300\end{array}$ & $\begin{array}{l}2015 C S=88 \\
\text { no } C S=339\end{array}$ & $\begin{array}{l}2016 C S=71 \\
\text { no CS }=258\end{array}$ & $\begin{array}{l}2017 C S=47 \\
\text { no } C S=228\end{array}$ \\
\hline & CS/No CS & CS/No CS & CS/No CS & CS/No CS \\
\hline Fewer than 5 antenatal checks, n (\%) & $57 / 21(54.3 / 7.1)$ & $50 / 35(56.8 / 10.4)$ & $32 / 29(45.1 / 11.2)$ & $26 / 25(55.3 / 11.0)$ \\
\hline Pregnancy diagnosis (weeks), mean \pm SD & $14 \pm 7 / 12 \pm 6$ & $13 \pm 8 / 12 \pm 6$ & $11 \pm 9 / 12 \pm 7$ & $12.5 \pm 9 / 11.4 \pm 6$ \\
\hline Pregnancy diagnosis at > 14 weeks, n (\%) & $50 / 72(59.5 / 28)$ & $33 / 88(52.4 / 26.2)$ & $22 / 62(40.7 / 25)$ & $17 / 56(44.7 / 24.8)$ \\
\hline GA at first syphilis test in pregnancy, mean $\pm \mathrm{SD}$ & - & $21 \pm 10 / 15 \pm 7$ & $15 \pm 12 / 14 \pm 8$ & $14 \pm 11 / 12 \pm 6$ \\
\hline First syphilis test $>14$ weeks, $\mathrm{n}(\%)$ & $30 / 116(70 / 39.3)$ & $42 / 134(79 / 40)$ & $31 / 112(69 / 44)$ & $34 / 80(89.5 / 35.4)$ \\
\hline $\mathrm{GA}$ at syphilis diagnosis, mean $\pm \mathrm{SD}$ & $24 \pm 11 / 17 \pm 8$ & $28 \pm 9 / 17 \pm 8$ & $21 \pm 15 / 16 \pm 10$ & $20 \pm 15 / 16 \pm 8$ \\
\hline Diagnosis of syphilis at delivery or puerperium, $\mathrm{n}(\%)$ & $64 / 5(59.8 / 1.7)$ & $35 / 5(39.8 / 1.5)$ & $26 / 2(36.6 / 0.8)$ & $17 / 2(36.2 / 0.9)$ \\
\hline Correct treatment, n (\%) & $3 / 260(3 / 96.7)$ & $8 / 335(9.1 / 99.1)$ & $18 / 236(26.9 / 95.1)$ & $4 / 212(9.3 / 99.5)$ \\
\hline Treated partners excluding missing data, $\mathrm{n}(\%)$ & $29 / 115(58 / 67.6)$ & $13 / 144(25.5 / 64.3)$ & $17 / 99(41.5 / 65.6)$ & $10 / 96(43.5 / 68.0)$ \\
\hline
\end{tabular}

CS congenital syphilis, SD standard deviation, GA gestational age

${ }^{\mathrm{a}}$ All denominators exclude cases with missing data 


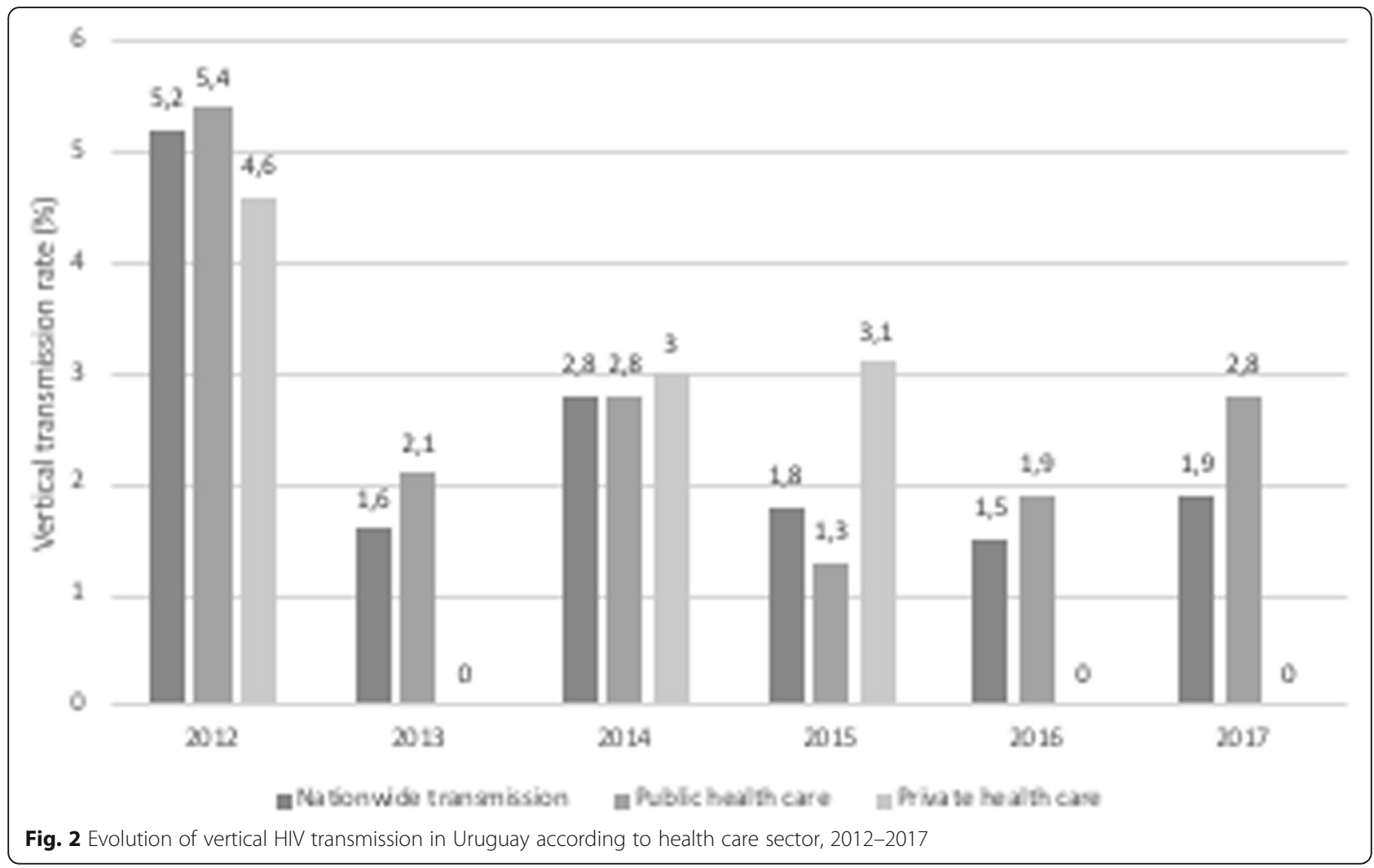

of the Americas reported data compatible with achievement of the goal and targets of HIV MTCT elimination, and 20 reported data compatibles with elimination of MTCT of syphilis [13].

A decline in congenital syphilis was observed for both public and private health care, except for public health care outside the capital metropolitan area. For the private health care sector, the rate in the interior of the country was higher than in the capital, possibly due to different quality of care, but it is already bellow the elimination rate. This suggests the need for a disaggregated evaluation of antenatal care indicators, with separate analysis of capital and non-capital geographical areas to identify possible failures in antenatal care for congenital syphilis prevention. Studies performed in developing countries have reported regional inequalities in antenatal care, resulting in part from difficulties in the access to health care services and low levels of economic development [14-16]. In New York city, in approximately one third of the reported cases of congenital syphilis from 2010 to 2016, the major contributing factor was late initiation of prenatal care, with lack of health care coverage often cited by patients as a barrier to seeking care. The authors concluded that absent or late prenatal care among mothers of infants with congenital syphilis suggests that pregnant women with syphilis might be unaware of available services or face barriers to obtaining prenatal care; this might be particularly applicable for women born outside the United States [17]. Also, in England, cases have been associated with mothers who were socially marginalized and encountered barriers when accessing antenatal care [18]. In Argentina, analyses utilizing data from SIP (2004-2009) also found a higher risk of maternal syphilis among mothers with no antenatal care and in unplanned pregnancies [19].

Among the cases of congenital syphilis in years 20142017 we found a higher frequency of congenital syphilis in the presence of late pregnancy diagnosis, fewer than 5 antenatal checks, delayed diagnosis of congenital syphilis at delivery or puerperium, lower rate of correct treatment of congenital syphilis, and untreated partners. The percentage of pregnant women who received antenatal care from skilled professionals was high in Uruguay (> $95 \%)$. However, the percentage of women with the first antenatal consultation before 20 gestational weeks ranged from 83.4 to $85.5 \%$. This shows the need to strengthen strategies to increase early antenatal care, especially in vulnerable women, since the performance of tests at the first antenatal check is high in the country. We did not find a higher frequency of congenital syphilis in any maternal age range, as reported by a Brazilian study that found an association with the mother being 
younger than 20 years [20], but the association of congenital syphilis with low educational attainment, delayed start of antenatal care, and fewer antenatal visits is well established in the literature [20-22].

A regional audit with 42 pregnant women with syphilis in England, found that the national standards were met in the majority of cases with $69 \%$ being treated according to national guidance and all cases completing treatment. Locally developed standards on multidisciplinary working and communication were met less well, with particular issues regarding the documentation of pregnancy outcomes in the records and communication between medical specialties being highlighted. The research resulted in a regional good practice guide to address standards not met, reduce adverse outcomes and prevent future cases of congenital syphilis [23].

Sociocultural vulnerability is an important factor in congenital syphilis. We observed a higher frequency of congenital syphilis in the groups of low maternal schooling, unplanned pregnancy, history of syphilis, and having other children with congenital syphilis. The prevalence of absent family planning in Uruguay remained around $33 \%$ from 2014 to 2016, showing a possible opportunity for action in the sense of providing better access to contraception, thus preventing unplanned pregnancies that usually lead to worse antenatal care. A significant decline in the fertility rate has been noted in the last biennium, especially among adolescents, following the availability and access to subdermal implants in the first level of care [24].

Preventing congenital syphilis is not technically difficult, however operational difficulties limit the effectiveness of programmes in many settings. A study conducted in Bolivia, Kenya, and South Africa found that early antenatal syphilis screening and management of positive cases were difficult to implement since most women presented for their first antenatal clinic visit after 6 months of pregnancy, the availability of the tests results was variable, and no clinic had a system for tracking RPR-reactive women who did not return for their results. The authors also mention a need to improve training and work conditions for the health-care providers and drugs availability [25].

In relation to congenital syphilis, several prevention strategies could be implemented at the primary care level, including encouraging women to attend antenatal care before the 4th month of pregnancy, providing point-of-care testing so that results are available immediately and women who test positive can be treated, implementing presumptive treatment of sexual partners of women who test positive, adding a second test later in pregnancy so that incident cases can be managed, and improving the quality of syphilis care during pregnancy, delivery, and the neonatal period [25].

Regarding MTCT of HIV, reporting via the routine information system was $100 \%$. Nevertheless, the case reviews focusing on infected newborns are still useful as an opportunity to identify points of system failure, including delayed pregnancy diagnosis, delay in the definition of maternal infection status even in women who began antenatal care after 14 pregnancy weeks, and lack of treatment adherence, among others. Regarding HIV, despite an early pregnancy diagnosis (on average 12 weeks), gestational age at HIV diagnosis has remained at 18-19 weeks. This might be explained by the use of immunoenzymatic assays as screening technique for HIV at the first routine testing in pregnancy, with communication of results only after a confirmation is obtained by Western-Blot, a deep-rooted practice among technicians, which persists despite the changes in diagnostic protocols. A decrease was noted in the diagnosis performed at delivery or immediate puerperium (rapid test).

Our study has strengths as the high coverage of the audits and the fact that the audits also take in account all positive mothers, not only positive neonates, increasing their capacity to find cases. These also allow the identification of weakness in the health care process and to perform feedback for the improvement process. As limitations we consider that, as a retrospective analysis, the identification of positive women occurs during delivery and post-partum. The ideal scenario was that a positive test in a pregnant woman, both for syphilis and HIV, would trigger an alert in the system allowing supervision of medical conducts and the adequate follow -up, helping to avoid cases of maternal to child transmission.

\section{Conclusions}

Case reviews of congenital syphilis in Uruguay have produced knowledge regarding the real number of cases and allowed an assessment of the status of EMTCT in the country. The results suggest that rates must be adjusted and provided an opportunity to improve the reliability of surveillance data. Also, there is a need to maintain routinely congenital syphilis case- studies as surveillance tool. For HIV, the case reviews showed the need to better inform health care professionals regarding diagnostic protocols. In relation to congenital syphilis, several prevention strategies could be implemented including encouraging women to attend antenatal care before the 4th month of pregnancy thus increasing the odds of pregnant women and their partners being diagnosed and treated earlier and improving health care workers training in congenital syphilis diagnostic and management. 


\section{Supplementary information}

Supplementary information accompanies this paper at https://doi.org/10. 1186/s12884-019-2516-z.

Additional file 1: Table S1. Sociocultural characteristics among congenital syphilis cases after a maternal diagnosis, Uruguay, 2015-2017. Table S2. Analysis of cases resulting in vertical HIV transmission, Uruguay, 2013-2017. (DOCX 34 kb)

\section{Abbreviations}

ART: Antiretroviral therapy; AZT: Azidothymidine; CS: Congenital syphilis; DEVISA: Bureau for Epidemiological Surveillance; EMTCT: Elimination of mother-to-child transmission; GA: Gestational age; HDI: Human development index; HIV: Human Immunodeficiency Virus; LBC: Electronic live birth certificate; MDGs: Millennium Development Goals; MTCT: Mother-to-child transmission; PAHO: Pan American Health Organization; RPR: Rapid Plasma Reagin; SD: Standard deviation; SIP: Perinatal Information System (Sistema Informático Perinatal); SNIS: Integrated National Health Care System (Sistema Nacional Integrado de Salud) SNSNational Health Insurance (Seguro Nacional de Salud): STI: Sexually transmitted infections; VDRL: Venereal Disease Research Laboratory; WHO: World Health Organization

\section{Acknowledgements}

Not Applicable.

\section{Authors' contributions}

SC, RG and MFS conceived the study. SC, AV, FG, RA and JQ contributed to survey development and statistical expertise. SC and MFS wrote the initial drafts of the paper and oversaw the editing process with input from RG, AV FG, RA, SS and JQ. All authors read and authorized the final manuscript before submission. All authors read and approved the final manuscript.

\section{Funding}

The authors have no financial relationships relevant to this article to disclose.

\section{Availability of data and materials}

The original data source for this article is available at https://www.gub.uy/ ministerio-salud-publica/tematica/itsvih-sida?page $=1$.

\section{Ethics approval and consent to participate}

Not required as all the data used in this manuscript was from routine surveillance data from the Ministry of Health of Uruguay and do not had any form of identify the participants.

\section{Consent for publication}

Not required. All data used in this manuscript was obtained from routine surveillance from the Ministry of Health of Uruguay. There was no way to identify the participants.

\section{Competing interests}

The authors declare that they have no competing interests. The authors are staff members of the Pan American Health Organization. The authors alone are responsible for the views expressed in this publication, and they do not necessarily represent the decisions or policies of the Pan American Health Organization.

\section{Author details}

${ }^{1}$ STI-HIV/AIDS Program Area, Public Health Ministry, Montevideo, Uruguay. ${ }^{2}$ Latin American Center of Perinatology, Women and Reproductive Health, Montevideo, Uruguay. ${ }^{3}$ Sexual and Reproductive Health Program Area, Public Health Ministry, Montevideo, Uruguay. ${ }^{4}$ Women's Health Program Area, Public Health Ministry, Montevideo, Uruguay. ${ }^{5}$ Public Health Ministry, Montevideo, Uruguay.
Received: 3 January 2019 Accepted: 20 September 2019

Published online: 04 November 2019

\section{References}

1. Global guidance on criteria and processes for validation of elimination of mother-to-child transmission of HIV and syphilis. 2nd ed. Geneva: World Health Organization (WHO) 2017:1-39.

2. World Health Organization (WHO). Millennium Development Goals (MDGs) https://www.who.int/topics/millennium_development_goals/about/en/ (accessed 14 Dec 2018).

3. Taylor M, Newman L, Ishikawa N, et al. Elimination of mother-to-child transmission of HIV and syphilis (EMTCT): process, progress, and program integration. PLoS Med. 2017:14:e1002329.

4. Pan American Health Organization. Strategy and Plan of Action for the Elimination of Mother-to-Child Transmission of HIV and Congenital Syphilis (Document CD50.R12) [Internet]. 50th Directing Council of PAHO, $2010 \mathrm{Sep}$ 27-Oct 1; Washington, D.C., PAHO; 2010 [Access 20 May 2019]. Available from: http://iris.paho.org/xmlui/handle/123456789/414

5. https://uins.msp.gub.uy (acessed 7 Nov 2018).

6. Pan American Health Organization (PAHO)/World Health Organization (WHO). Objetivos Sanitarios Nacionales 2020: hacia dónde irá la salud del país. Washington: PAHO 2017. https://www.paho.org/uru/index. php?option=com_content\&view=article\&id=1007:objetivos-sanitariosnacionales-2020-hacia-donde-ira-la-salud-del-paa-s\&ltemid=340 (accessed 3 Sep 2018).

7. Ministerio de Salud Pública (MSP). Recomendaciones para realizar consejería en VIH con énfasis en poblaciones vulnerables y nuevos algoritmos diagnósticos. Uruguay: MSP 2014:1-33. http://www.msp.gub.uy/sites/ default/files/Recomendaciones\%20consejeria\%20VIH\%20en\%20poblacion\%2 Ovulnerable\%202014.pdf (accessed 27 Aug 2018).

8. Ministerio de Salud Pública (MSP). Dirección General de la Salud. Área de Salud Sexual y Reproductiva. Guía clínica para la eliminación de la sífilis congénita y transmisión vertical del VIH. 2nd ed. Uruguay: MSP 2015:1-68. http://www.msp.gub.uy/sites/default/files/Guia\%20clinica\%20prevencion\%2 0sifilis\%20congenita\%20y\%20transmision\%20vertical\%202015 1.pdf (accessed 7 Nov 2018)

9. Instituto Nacional de Estadística (INE). Estimaciones y proyecciones de población (revisión 2013). http://www.ine.gub.uy/estimaciones-yproyecciones (accessed 7 Nov 2018).

10. United Nations Development Programme (UNDP). Informe sobre Desarrollo Humano 2016 - Desarrollo humano para todos. New York: UNDP 2016. http://hdr.undp.org/sites/default/files/HDR2016_SP_Overview_Web.pdf (accessed 7 Nov 2018)

11. Uruguay: panorama general. Uruguay: Banco Mundial 2017. http://www. bancomundial.org/es/country/uruguay/overview (accessed 7 Nov 2018).

12. Quiñones P, Franciulli A, Greif D, et al. Resultados de la validación de formulario nacional de auditoría de sífilis gestacional y congénita en el Centro Hospitalario Pereira Rossell. Rev Med Urug 2014:30:226-34. [Access 20 May 2019]. Available from: http://www.scielo.edu.uy/pdf/rmu/ v30n4/v30n4a03.pdf

13. Pan American Health Organization. Elimination of Mother-to-Child Transmission of HIV and Syphilis in the Americas.Update 2016. Washington, DC: PAHO. p. 2016.

14. Magadi MA, Madise NJ, Rodrigues RN. Frequency and timing of antenatal care in Kenya: explaining the variations between women of different communities. Soc Sci Med. 2000;51:551-61.

15. Addai I. Determinants of use of maternal-child health services in rural Ghana. J Biosoc Sci. 2000;32:1-15.

16. Osorio AM, Tovar LM, Rathmann K. Individual and local level factors and antenatal care use in Colombia: a multilevel analysis. Cad Saude Publica. 2014;30:1079-92.

17. Slutsker JS, Hennessy RR, Schillinger JA. Factors contributing to congenital syphilis cases - New York City, 2010-2016. MMWR Morb Mortal Wkly Rep. 2018;67:1088-93.

18. Martina F, Helen F, Hamish M, lan S, Paul V, Sharon W, Kirsty F, Margaret K, André C, Bhavita V, Claire R, Noel G, Gwenda H. Factors associated with four atypical cases of congenital syphilis in England, 2016 to 2017: an ecological analysis. Euro Surveill. 2017;22(49):10.2807/1560-7917.

19. Karolinski A, Mercer R, Bolzán A. Proyecto Investigación operativa “Utilidad del Sistema Informático Perinatal (SIP): gestión para la vigilancia epidemiológica de la Sífilis materna y sífilis congénita en una red de 
hospitales públicos del área metropolitana de Buenos Aires, Argentina: informe final. Montevideo: CLAP/SMR; 2012. (CLAP/SMR. Publicación científica; 1592). [Access 20 May 2019]. Available from: https://www.paho. org/clap/index.php?option=com_docman\&view=download\&category_slug= publicaciones-sifilis\&alias=285-utilidad-del-sip-gestion-para-la-vigilanciaepidemiologica-de-la-sifilis-materna-y-sifilis-congenita-en-argentina-2 \&ltemid=219\&lang=es

20. Nonato SM, Melo AP, Guimarães MD. Syphilis in pregnancy and factors associated with congenital syphilis in Belo Horizonte-MG, Brazil, 2010-2013. Epidemiol Serv Saude. 2015;24:681-94.

21. Soares $L G$, Zarpellon $B$, Soares $L G$, et al. Gestational and congenital syphilis: maternal, neonatal characteristics and outcome of cases. Rev Bras Saude Matern Infant. 2017:17:791-9.

22. Domingues RM, Leal Mdo C. [Incidence of congenital syphilis and factors associated with vertical transmission: data from the Birth in Brazil study]. Cad Saude Publica 2016;32(6):e00082415.

23. Hussey J, Mitchell L, Hew Y, Foster K, Waldram A. Preventing congenital syphilis - a regional audit of syphilis in pregnant women seen in Genitourinary Medicine services. Int J STD AIDS. 2014;25(6):448-51.

24. Ministerio de Salud Pública (MSP). Estadísticas Vitales. Uruguay: MSP 2017. http://www.msp.gub.uy/EstVitales (accessed 10 Sep 2018).

25. Deperthes BD, Meheus A, O'Reilly $\mathrm{K}$, et al. Maternal and congenital syphilis programmes: case studies in Bolivia, Kenya and South Africa. Bull World Health Organ. 2004;82:410-6.

\section{Publisher's Note}

Springer Nature remains neutral with regard to jurisdictional claims in published maps and institutional affiliations.

Ready to submit your research? Choose BMC and benefit from:

- fast, convenient online submission

- thorough peer review by experienced researchers in your field

- rapid publication on acceptance

- support for research data, including large and complex data types

- gold Open Access which fosters wider collaboration and increased citations

- maximum visibility for your research: over $100 \mathrm{M}$ website views per year

At $\mathrm{BMC}$, research is always in progress.

Learn more biomedcentral.com/submissions 